\title{
Renal damages in patients with major $\beta$-thalassemia
}

\author{
Maliheh Najafpour $^{(\mathbb{D}}$, Majid Farshdousti-Hagh ${ }^{2 * \mathbb{}}$, Ali Akbar Movasagpoor-Akbari ${ }^{{ }^{\circledR}}$, \\ Abbas-Ali Hosein-Poor Feyzi², Majid Malaki ${ }^{\mathbb{D}}$ \\ ${ }^{1}$ Medical Biotechnology Research Center, School of Nursing, Midwifery and Paramedical, Guilan University of Medical Sciences, Rasht, Iran \\ ${ }^{2}$ Hematology and Oncology Research Center, Tabriz University of Medical Sciences, Tabriz, Iran
}

\section{A R T I C L E IN F O}

Article Type:

Original

\section{Article History:}

Received: 5 February 2018

Accepted: 12 May 2019

Published online: 20 July 2019

Keywords:

Thalassemia

Renal function

Iron chelator therapy

\begin{abstract}
A B S T R A C T
Introduction: Numerous studies have shown the presence of renal dysfunction in patients with beta thalassemia major ( $\beta \mathrm{TM})$. According to iron overload and effects on renal, evaluation of renal function in $\beta$ TM can cause better control of them.

Objectives: In this study, we evaluated renal function in children and adults with $\beta$ TM.

Patients and Methods: Sixty patients (38 male and 22 female) with $\beta$ TM, and 60 healthy control subjects ( 25 males and 35 females), were participated in this cross-sectional study. Biochemical and urine analysis were conducted to evaluate renal function. Additionally, patients were classified based on the administration of iron chelators including deferoxamine (Desferal), deferiprone (L1), deferasirox (Exjade) and combination therapy.

Results: Renal dysfunctions such as hyperfiltration and proteinuria were common findings in patients compared with the normal group. Hypercalciuria was found only in patients groups receiving Exjade. Hyperfiltration was detected in all patients. Proteinuria was no related to drug administration.

Conclusion: We found a high percentage of our $\beta$ TM patients who had renal dysfunction as evidenced by proteinuria and hyperfiltration.
\end{abstract}

Implication for health policy/practice/research/medical education:

Renal dysfunction is a side effect of blood transfusion in patients suffering from beta thalassemia major ( $\beta$ TM). It seems that high percentage of patients with $\beta$ TM have renal dysfunction as evidenced by proteinuria and hyperfiltration. Hypercalciuria and hyperfiltration are some of the side effects of iron chelator agents.

Please cite this paper as: Najafpour M, Farshdousti-Hagh M, Movasagpoor-Akbari AK, Hosein-Poor Feyzi AA, Malaki M. Renal damages in patients with major $\beta$-thalassemia. J Nephropharmacol. 2020;9(1):e02. DOI: 10.15171/npj.2020.02

\section{Introduction}

Thalassemia is the most common single gene disorder around the world. This disease as a type of chronic, microcytic and inherited anemia, is associated with defects in hemoglobin synthesis and reduced life span of red blood cells (1). Beta thalassemia major ( $\beta \mathrm{TM})$ is more common than alpha thalassemia (2). Due to newborn screening, regular blood transfusion, and effective treatment with iron chelators, the survival rate and quality of life for patients with beta thalassemia had significant progress in recent decades, however, disease complications are still a great challenge in these patients $(2,3)$.

One of the major complications is iron overload, which leads to multi-organ malfunctions such as heart, liver and kidney (4). For the first time in 1975, renal dysfunction in patients with $\beta \mathrm{TM}$ was reported (5). Iron deposition in renal tubules is the main cause of renal damage. Red blood cells hemolysis due to hypoxia is also involved in renal damage. It has been shown that hypoxia has the most influence on renal tubules (6). In addition, iron chelating agents could contribute to the tissue damage $(7,8)$. Some of the renal complications in patients with $\beta$ TM include increased renal plasma flow, failure of urine concentration, renal tubular acidosis, renal tubulopathy such as hypercalciuria and proteinuria (3-5,9).

\section{Objectives}

The aim of the present study was to compare renal function markers such as hypercalciuria, proteinuria and renal function in patients with $\beta$ TM and healthy control subjects. 


\section{Patients and Methods}

Protocol of the study

Sixty patients (38 male and 22 female), were enrolled in this study. All of them are suffered from major beta thalassemia. Diagnosing criteria were consisted of; mean cell volume less than $80 \mathrm{fL}$, mean cell hemoglobin less than 27 pg, $\mathrm{F}$ hemoglobin about $98 \%$ and A2 hemoglobin about $2 \%$. Additionally, 60 healthy control subjects selected as control group. All patients were in stable stage of their disease with regular transfusion of 1-2 times in a month to maintain pre-transfusion hemoglobin level above 9 g/dL. Patients under the treatment with iron chelation therapy divided into four groups, including desferal (deferoxamine), deferiprone (L1), Exjade (deferasirox) and combination (desferal+L1) therapy. Patients with minor beta thalassemia, minor beta thalassemia combined with iron deficiency, intermedia beta thalassemia, other hemoglobinopathies, recurrent urinary tract infection, patients who administered nephrotoxic drugs and other major anomalies, considered as excluded criteria. The demographic conditions, including age, gender, age of diagnosis, blood pressure, body temperature, have obtained through interviews and reviews of hospital reports. Fasting blood and fresh morning urine samples were collected for biochemical analysis. Serum and urine were separated and kept frozen at $-70^{\circ} \mathrm{C}$ until time of analysis. The determination of fasting blood suger (FBS), urea, creatinine and albumin, urine creatinine, calcium and total protein assessed by standard commercial kits. Additionally, random urine samples evaluated for proteinuria [urinary protein/creatinine ratio (mg/ $\mathrm{mg})$, calciuria [urinary $\mathrm{Ca} /$ creatinine ratio $(\mathrm{mg} / \mathrm{mg})$ ] and macroscopic analysis. For proteinuria, the values < $0.5 \mathrm{mg} / \mathrm{mg}$ considered as normal; $0.5-2 \mathrm{mg} / \mathrm{mg}$ showed proteinuria and values more than $2 \mathrm{mg} / \mathrm{mg}$ showed renal damage. For calciuria, values $<0.21 \mathrm{mg} / \mathrm{mg}$ considered as normal for ages above two years since, values above this ratio considered as increased or abnormal. Glomerular filtration rate (GFR) evaluated with both CG (CockcroftGault equation) and MDRD (Modification of Diet in Renal Disease) formula. According to Brochner-Mortensen, patients who had GFR of $90-130 \mathrm{~mL} / \mathrm{min} / 1.73 \mathrm{~m}^{2}$ were considered as normal, while values higher than $130 \mathrm{~mL}$ / $\mathrm{min} / 1.73 \mathrm{~m}^{2}$ were considered as cases of hyperfiltration, since, values lower than $60 \mathrm{~mL} / \mathrm{min} / 1.73 \mathrm{~m}^{2}$ showed renal damage.

\section{Ethical issues}

The research followed the Tenets of the Declaration of Helsinki. Informed consent was obtained in every case from them and/or their legal guardians. All patients took part in this study voluntarily. The research was approved by the ethical committee of Tabriz University of Medical Sciences, Tabriz, Iran (ethical code \#5.4.849). All results retrieved from the thesis of Maliheh Najafpour which was conducted in Tabriz University of Medical Sciences (Thesis \# 91.2-3.8).

\section{Statistical analysis}

Results were determined as mean \pm SD. Statistical analysis was performed by using Statistical Package for Social Sciences (SPSS) version 16. T-test and correlation test were used for comparison of quantitative variables. For qualitative variables we used chi-square test. Accordingly, $P$ value of less than 0.05 was regarded as statistically significant.

\section{Results}

Sixty patients (38 male and 22 female) with major beta thalassemia and 60 healthy control subject (25 male and 35 female) were enrolled in our study. The ages of patients were between 3-34 years old (median; 17 years). The mean age of patients was 16 years old (median; 17 years). The mean of disease diagnosis age was 20 months. Comparison of some renal function markers between patients with $\beta \mathrm{TM}$ and healthy control subjects showed that calciuria had no significant difference $(P=0.8)$, whereas hyperfiltration (GFR; $P=0.00$ by MDRD and $P=0.001$ by $C G)$ and proteinuria $(P<0.05)$ (Table 1$)$ were common findings. Serum albumin $(4.17 \pm 0.32 \mathrm{~g} / \mathrm{dL})$ and urea $(20.23 \pm 5.86 \mathrm{mg} / \mathrm{dL})$ were in normal range. Also GFR had correlation with age (CG: $\mathrm{R}^{2}: 0.323$ versus MDRD: $\mathrm{R}^{2}$ 0.4839 ) as shown in Figures 1 and 2. Patients classification

Table 1. Comparison of some renal function markers between patients with $\beta T M$ and healthy control subjects

\begin{tabular}{lccc}
\hline & Patient & Control & $\boldsymbol{P}$ \\
\hline Calciuria \pm SD & $0.67 \pm 0.07$ & $0.69 \pm 0.05$ & 0.8 \\
Proteinuria \pm SD & $0.05 \pm 0.06$ & $0.02 \pm 0.01$ & 0.000 \\
GFR (MDRD) \pm SD & $154 \pm 66$ & $101 \pm 31$ & 0.000 \\
GFR (CG) \pm SD & $151 \pm 64$ & $121 \pm 29$ & 0.001 \\
\hline
\end{tabular}

GFR, glomerular filtration rate; MDRD, Modification of Diet in Renal Disease; CG, Cockcroft-Gault equation.

Data are presented as mean \pm SD.

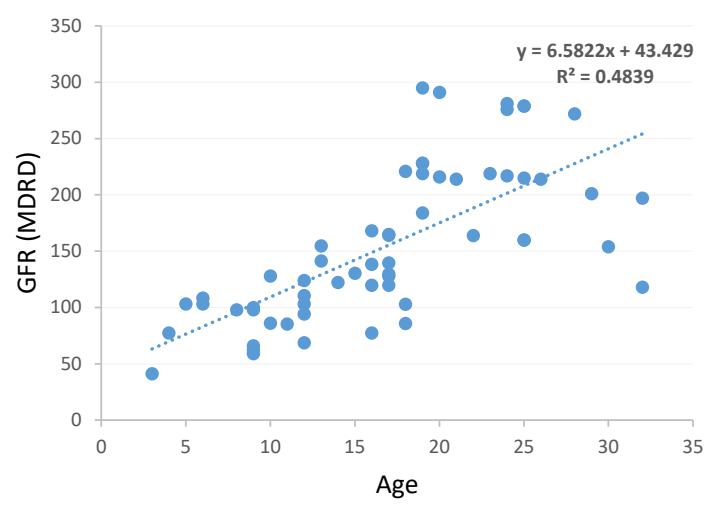

Figure 1. Correlation of estimated GFR (MDRD) with age. 
based on the consumption of four groups of iron chelators including; 31 of them received Desferal (deferoxamine), 16 of them received Exjade (deferasirox), 5 of them were on L1 (deferiprone) and 7 of them received combination

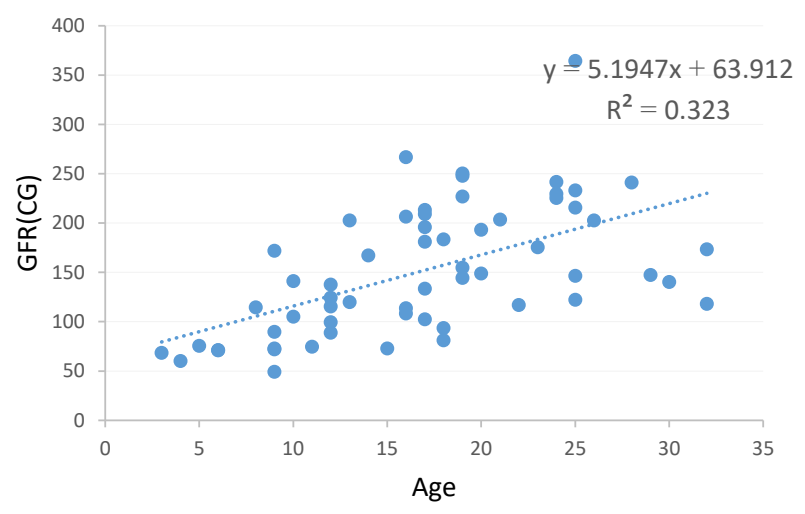

Figure 2. Correlation of estimated GFR (CG) with age.

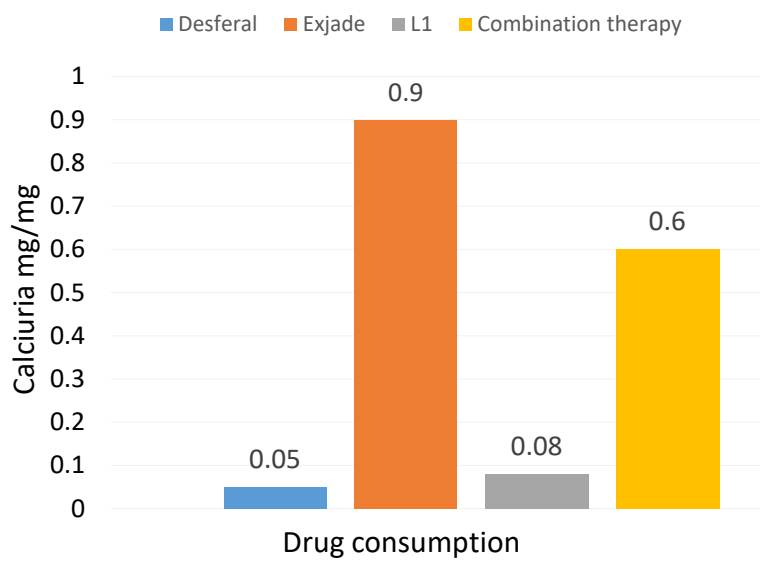

Figure 3. Calciuria in patients were classified according to the administration of iron chelators.

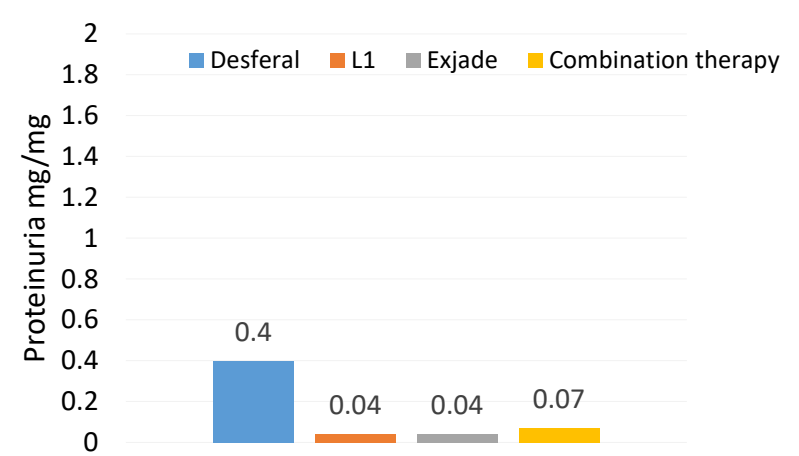

Drug consumption

Figure 4. Proteinuria in patients were classified according to the administration of iron chelators. therapy. Hypercalciuria was found only in patients' groups receiving Exjade $(0.9 \pm 0.08 \mathrm{mg} / \mathrm{mg}$ ) (Figure 3$)$. Proteinuria was not related to drug consumption $(<0.5 \mathrm{mg} / \mathrm{mg})$ (Figure 4). Hyperfiltration was shown in all patients (MDRD; 210 $\pm 50 \mathrm{CC} / \mathrm{min}$ and CG: $176 \pm 39 \mathrm{CC} / \mathrm{min}$ ) (Figures 5 and 6).

\section{Discussion}

Dysfunction in body organs in patients with $\beta \mathrm{TM}$ is one of the most important side effects of blood transfusion (4). In this regard, some data are available about heart and liver injuries but investigation regarding kidney dysfunction is limited since its early detection is considered an important problem (3-6,9-11). Renal dysfunctions such as hyperfiltration and proteinuria were common findings in patients compared with the control group. The present study was similar to the studies conducted by SadeghiBojd et al (4) and Ali \& Mahmoud (12) in which patients with $\beta$ TM had renal damage, such as hypercalciuria, proteinuria, glycosuria and magnesiumuria. In their study, GFR was not measured, as we know GFR depends on some

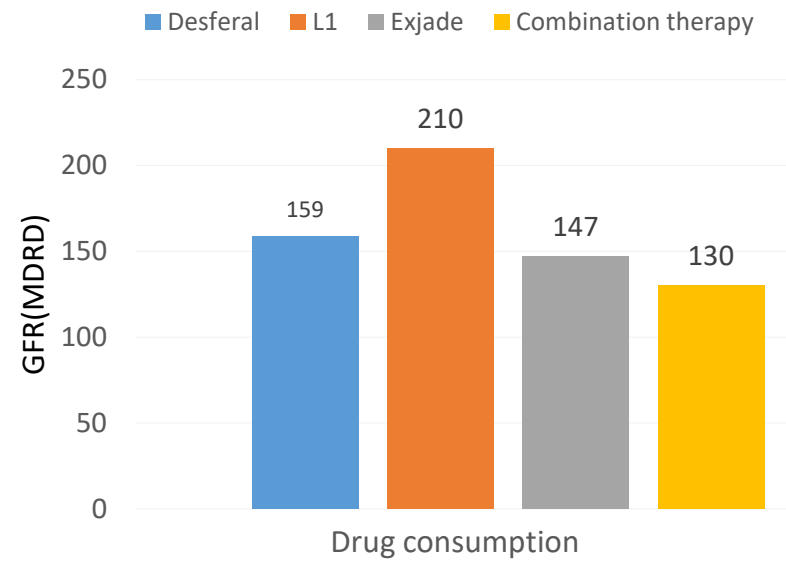

Figure 5. GFR MDRD in patients were classified according to the administration of iron chelators.

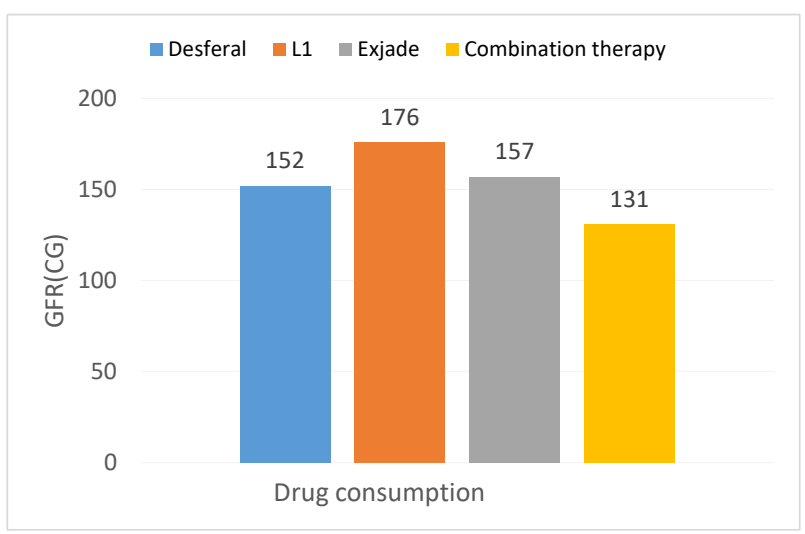

Figure 6. GFR (by CG) in patients were classified according to the administration of iron chelators. 
factors such as height, age, weight, race and gender. Our study was in contrast to the study performed by Lai et al (10) in which $\beta$ TM patients had normal GFR during a ten years follow-up. Abnormal GFR was seen only in patients with tubulopathy, despite proteinuria and calciuria (11). Additionally, the present study was similar to the study by Malaki et al (14), in which increased GFR (hyperfiltration) in patients with $\beta \mathrm{TM}$ was observed. However, in the present study increased GFR was significantly more than their study. This finding might be partly related to age range of the participants. Hypercalciuria was found only in patients group receiving Exjade, while, hyperfiltration was shown in all patients. Proteinuria was not related to drug administration. There are few studies resulting from drug administration such as pomp malfunction or dialysis after use of deferoxamine, like acute kidney injury (16) or elevation in serum creatinine (17). In conclusion, high percentage of patients with $\beta$ TM have renal dysfunction as evidenced by proteinuria and hyperfiltration. More studies are needed to detect early markers for renal dysfunction in $\beta$ TM such as serum cystatin $C$ and $\beta 2$ microglobulin.

\section{Conclusion}

This research aimed to evaluate renal function in children and adults with $\beta$ TM. Renal dysfunctions such as proteinuria and hyperfiltration are common findings in $\beta$ TM patients. Hypercalciuria was found only in patients group receiving Exjade, since hyperfiltration was shown in all patients. Proteinuria wasn't related to drug administration.

\section{Limitations of the study}

We could not measure early biomarkers such as cystatin $\mathrm{C}$ or $\beta 2$ microglobulin. We suggest further studies on this aspect of patients with major $\beta$-thalassemia.

\section{Acknowledgments}

This work was partially supported by Tabriz Hematology and Oncology Research Center and Children hospital and Vice Chancellor Research of Tabriz University of Medical Sciences. We thanks Dr. Arami Medical laboratory (in Tabriz) for helping us in collecting samples from healthy patients. Finally special thanks of Mehdi Talebi (faculty of member of Tabriz University of Medical Sciences) for helping us in practical work.

\section{Authors' contribution}

$\mathrm{MN}$; conceived the idea, performed experiments, wrote the manuscript,. MFH; directed the work, performed experiments and editing the manuscript. AAMA; directed the work and editing the manuscript. AAHPF; directed the work and editing the manuscript. MM; performed experiments and statistical analysis. All of authors read and approved the final manuscript.

\section{Conflicts of interest}

The authors declared no conflicts of interest.

\section{Ethical considerations}

Ethical issues (including plagiarism, misconduct, data fabrication, falsification, double publication or submission, redundancy) have been completely observed by the authors.

\section{Funding/Support}

This manuscript was extracted from MSc thesis supported financially by Deputy of Research of Tabriz University of Medical Sciences (grant\# 91.2-3.8). The authors are grateful to all who helped in conducting the present study.

\section{References}

1. Tunaci M, Tunaci A, Engin G, Ozkorkmaz B, Dinçol G, Acunaş G, et al. Imaging features of thalassemia. Eur Radiol. 1999; 9:1804-9. doi: 10.1007/s003300050926.

2. Azar Keivan A, Eshghi P, Karimi M, Badiyi Z, Aghighi M. Comprehensive package of care for patients with thalassemia. ist ed. Tehran: Avij; 2006.

3. Hamed EA, ElMelegy NT. Research renal functions in pediatric patients with beta-thalassemia major: relation to chelation therapy: an original prospective study. Ital J Pediatr. 2010;36:39.

4. Sadeghi-Bojd S, Hashemi M, Karimi M. Renal tubular function in patient with beta thalassemia major in Zahedan, Southest Iran. Singapore Med J. 2008;49:410.

5. Mastrangelo F, Lopez T, Rizzelli S, Manisco G, Corliano C, Alfonso L. Function of the kidney in adult patients with Cooley's disease. A preliminary report. Nephron. 1975; 14:229-236.doi: 10.1159/000180452.

6. Kalman S, Attay AA, Sakallioglu O, Ozgurtas T, Gok F, Kurt I, et al. Renal tubular function in children with betathalassemia minor. Nephrology (Carlton). 2005; 10:4279.doi: 10.1111/j.1440-1797.2005.00484.x.

7. Koren G, Bentur Y, Strong D, et al. Acute changes in renal function associated with deferoxamine therapy. Am J Dis Child. 1989;143:1077-1080.

8. Cianciulli P, Sollecito D, Sorrentino F, Forte L, Gilardi E, Massa A, et al. Early detection of nephrotoxic effects in thalassemic patients receiving desferrioxamine therapy. Kidney Int.1994; 46:467-470.

9. Voskaridou E, Terpos E, Michail S, Hantzi E, Anagnostopoulos A, Margeli A, et al. Early markers of renal dysfunction in patient with sickle sickle/ beta thalassemia. Kidney Int. 2006;69:2037-2042. doi: $10.1038 /$ sj.ki.5000248.

10. Lai ME, Spiga A, Vacquer S, Carta MP, Corrias C, Ponticelli C. Renal function in patients with $\beta$-thalassaemia major: a long-term follow-up study. Nephrol Dial Transplant. 2012; 27:3547-51.

11. Dimitriadou M, Christoforidis A, Economou M, Teli A, Printza N, Tzimouli V, et al. Fok-I polymorphism of vitamin $\mathrm{D}$ receptor gene and the presence of renal disfunction in patient with beta-thalassemia major. Pediatr Hematol Oncol. 2011;28:509-16. doi: 10.3109/08880018.2011.579231. 
12. Ali BA, Mahmoud AM. Frequency of glomerular dysfunction in children with Beta thalassaemia major. Sultan Qaboos Univ Med J. 2014;14(1):e88-94.

13. Hosseinzadeh M, Moradi nokhodchari A, Yaghut M. Prevalence of renal tubular dysfunction in beta thalassemia minor in Shiraz. J Fasa Univ Med Sci. 2012;4:137-41.

14. Malaki M, Sari Sorkhabi R, Shoaran M, Bagheri S. Beta thalassemia major: the effect of age on glomerular filtration rate. Saudi J Kidney Dis Transpl. 2011;22:963-8.

15. Roos JF, Doust J, Tett SE, Kirkpatrick CM. Diagnostic accuracy of cystatin $\mathrm{C}$ compared to serum creatinine for the estimation of renal dysfunction in adults and children-a meta-analysis. Clin Biochem. 2007;40:383-91.

16. Ponticelli C, Musallam KM, Cianciulli P, Cappellini MD. Renal complications in transfusion-dependent beta thalassaemia. Blood. 2010;24:239-44.

17. Cappellini MD, Cohen A, Piga A, Bejaoui M, Perrotta S, Agaoglu L, et al. A phase 3 study of deferasirox (ICL670), a once-daily oral iron chelator, in patients with betathalassemia. Blood. 2006;107:3455-62. doi: 10.1182/ blood-2005-08-3430.

Copyright $\odot 2020$ The Author(s); Published by Published by Society of Diabetic Nephropathy Prevention. This is an open-access article distributed under the terms of the Creative Commons Attribution License (http://creativecommons.org/licenses/by/4.0), which permits unrestricted use, distribution, and reproduction in any medium, provided the original work is properly cited. 